\title{
Acerca de la distribución de las editoriales independientes argentinas (2011-2015)
}

\section{About the distribution of Argentine independent publishers (2011- 2015)}

ARTÍCULO

\section{Gustavo Velázquez \\ Universidad Nacional de Quilmes, Argentina. Contacto: gdvelazquez90@gmail.com}

Recibido: agosto de 2020

\section{Resumen}

El presente trabajo propone reflexionar acerca de la distribución editorial en tanto problema para las editoriales argentinas contemporáneas. Especialmente, se estudia a los proyectos de pequeña y mediana escala, también conocidos como editoriales independientes, durante el periodo 2011-2015. En este tema influye la posición dominante de los grandes grupos editoriales que acaparan gran parte de la distribución y comercialización, cuestión que pone en tensión a los actores de menor porte económico, que apelan a distintas estrategias para resolver la circulación comercial de sus publicaciones y posicionarse dentro del campo editorial.

Palabras claves: Campo editorial; Distribución editorial; Editoriales independientes argentinas.

\begin{abstract}
The present work proposes to reflect on the editorial distribution as a problem for contemporary Argentine publishing houses. Especially, small and medium-scale projects, also known as independent publishers, are studied during the period 2011-2015. This issue is influenced by the dominant position of the large publishing groups that monopolize a large part of the distribution and commercialization, an issue that puts in tension the smaller economic actors, who appeal to different strategies to resolve the commercial circulation of their publications and position themselves within the editorial field.
\end{abstract}

Keywords: Editorial field; Editorial distribution; Argentine independent publishers.

\section{Introducción}


La distribución es una fase importante de la cadena de valor del libro. Este proceso resulta vertebrador para toda actividad editorial dado que se vincula con la circulación y acceso a los libros. Es decir, interfiere en las posibilidades de venta de las empresas editoriales y, por ende, afecta a la economía particular de estos proyectos; y, a su vez, determina las maneras de acceso de los lectores a determinadas producciones editoriales.

Todo editor se ve obligado a resolver la forma en que distribuirá su catálogo, de acuerdo a las expectativas y las posibilidades financieras de su proyecto editorial. En este sentido, las condiciones del mercado, el cual presenta altos niveles de concentración en pocas empresas multinacionales, genera dificultades para las pequeñas y medianas editoriales respecto a la circulación comercial. Estas editoriales, también llamadas independientes, se desenvuelven en base a escalas económicas reducidas, por lo que se encuentran en desventaja ante la posición dominante de las grandes empresas. En consecuencia, muchas de estas editoriales apelan a diversas estrategias, algunas alternativas e innovadoras, para dar respuesta a este problema.

El presente artículo tiene por objetivo analizar las condiciones de distribución de las editoriales independientes argentinas, entre 2011 y 2015. Para esto se establecen los siguientes objetivos específicos: identificar las problemáticas de las editoriales independientes en relación a la distribución y comercialización; y analizar las estrategias de este tipo de editoriales para resolver la distribución.

\section{Consideraciones metodológicas}

Los argumentos de este artículo se desprenden de la tesis Letra chica: producción, distribución y comercialización de las editoriales independientes (2011-2015). Esta investigación se enfocó en analizar las dinámicas de profesionalización de las llamadas editoriales independientes, desde el análisis de las rutinas productivas, sustentada en el estudio de caso múltiple de un conjunto de sellos independientes de Ciudad Autónoma de Buenos Aires. ${ }^{1}$

Este trabajo, por tanto, posee una estrategia metodológica cualitativa, basada principalmente en dos herramientas de recolección/construcción de datos. Por un lado, la realización de entrevistas semiestructuradas y en profundidad a editores independientes. Esta instancia permitió conocer la experiencia de los proyectos editoriales respecto al modo en que resuelven las distintas etapas del quehacer editorial, en especial, la distribución. En este sentido, el estudio de casos llevó a la identificación de la distribución como un aspecto problemático para las editoriales de pequeño y mediano porte económico.

\footnotetext{
1 Los casos relevados en la tesis son: Ediciones del Signo, Ediciones Godot, Lenguaje Claro, Eterna Cadencia, Grupo Editorial Sur, Gourmet Musical, Biblos, Peces de Ciudad, Alto Pogo, Marea Editorial, Nulú Bonsai, Santiago Arcos, Las Cuarenta, Chirimbote, Punto de Encuentro, Entropía, CICCUS y Patria Grande.
} 
Por otro lado, la información recabada en las entrevistas es acompañada del relevamiento de fuentes secundarias para un análisis acabado del objeto de estudio. Esto corresponde a la revisión de informes elaborados por organismos especializados en la industria del libro nacional (Informe de producción del libro argentino perteneciente a la Cámara Argentina del Libro y La industria del libro en Argentina del Centro de Estudios para la Producción) y de bibliografía especializada. Respecto a esto último, se recuperan los aportes de autores destacados del campo de estudios del libro y la edición, tales como Robert Darnton (2010) y Pierre Bourdieu (2000, 2002), en el plano internacional, y Alejandro Dujovne (2017, 2019), Daniela Szpilbarg (2015; 2019) y Ezequiel Saferstein (2014), en el plano nacional.

\section{Características y tensiones en el campo editorial nacional}

El sociólogo Pierre Bourdieu (2002) desarrolla el concepto de campo intelectual, el cual define como el "sistema de las relaciones que se establecen entre los agentes del sistema de producción intelectual" (Bourdieu, 2002, p.4). Este campo posee determinadas características respecto a las posiciones que ocupan los agentes que lo componen, las cuales se hallan jerarquizadas y, por ende, se instalan como espacios de disputa de poder.

En este sentido, Bourdieu se ha interesado en el mundo editorial como un campo específico, vinculado a la consagración en el mundo del libro, en el que intervienen una serie de instituciones y actores, y donde una obra literaria adquiere notoriedad pública. Al respecto, la práctica de edición ocupa un lugar relevante en la constitución de legitimidad social y cultural, dado que "el editor es el que tiene el poder totalmente extraordinario de asegurar la publicación, es decir, de hacer acceder un texto y un autor a la existencia pública, conocido y reconocido" (Bourdieu, 2000, p.223).

En el campo editorial se dan conflictos y tensiones ideológicas, políticas y económicas. Aquí juegan los agentes tradicionales del sector (empresas editoriales, editores, autores, distribuidores, libreros, etcétera), los nuevos players ligados a las estructuras tecnológicas y digitales, y el Estado. En este "campo de batalla", por tanto, conviven proyectos de diferente signo y percepción en torno al libro y la edición, a lo que remiten variados modelos de negocio y participación del mercado.

Tomando el modelo de circuito de la comunicación que desarrolla el historiador Robert Darnton (2010) para comprender las condiciones sociales, económicas, políticas e intelectuales de la producción, circulación y recepción de los libros, todos los actores involucrados en la actividad editorial se encuentran en relación y el trabajo de cada uno se liga con el del otro. A partir de esta idea es posible pensar el campo editorial desde las prácticas y las redes que construyen los distintos agentes entre sí mediadas por el dispositivo libro. 
El campo editorial nacional, particularmente, presenta fuertes asimetrías en la distribución del capital simbólico y económico. El fenómeno de la concentración ha generado diferentes mutaciones en este ámbito. Este proceso, sucedido durante finales de la década del '80 y con mayor intensidad en la del '90, consistió en el arribo de grandes empresas editoriales multinacionales en el país, que se encargaron de absorber muchas editoriales nacionales, a través de compras o fusiones (Botto, 2006). El resultado de estas maniobras económicas financieras ha sido la conformación de grandes grupos editoriales - actualmente prácticamente los grupos editoriales Grupo Planeta y Penguin Random House (Dujovne, 2017) dominan el mercado.

Estos grandes grupos se caracterizan, mayormente, por: la orientación hacia la venta masiva, al bajo riesgo y a la alta rentabilidad, con foco en los títulos de éxito inmediato en detrimento de los títulos de "fondo de catálogo"; la introducción de las lógicas del marketing y de las metas financieras en el trabajo editorial; la reducción de la calidad en los procesos y en los productos; la adquisición de pequeñas y medianas editoriales, con cambios intensos en sus modos de funcionamiento y en la selección de títulos (De Souza Muñiz Júnior, 2015, p.145). Las lógicas de los grupos editoriales, en tanto acumuladores de capital económico y simbólico, ponen en tensión la dinámica clásica de la actividad editorial: de una economía centrada en la oferta a una economía centrada en la demanda (Saferstein, 2014).

Como contracara del proceso de concentración, desde los años ' 90 y en mayor medida a partir de los primeros años del nuevo milenio, se ha destacado el surgimiento de nuevos actores en el campo editorial ${ }^{2}$. Estos emprendimientos llamados "independientes" se desarrollan de manera alternativa a las grandes editoriales a partir de políticas editoriales alejadas de las lógicas meramente comerciales (Saferstein y Szpilbarg, 2014; Szpilbarg, 2019). Se trata, a grandes rasgos, de proyectos editoriales de baja escala económica, desarrollados por fuera de la órbita de los grandes grupos editoriales (Gazzera, 2016), que satisfacen pequeños segmentos de la demanda. Estos actores ocupan un lugar relevante en la reconfiguración del mapa editorial nacional ${ }^{3}$.

El sector editorial independiente está marcado por su profunda complejidad y heterogeneidad (Vanoli y Saferstein, 2011). Dentro de este conjunto se encuentran diferentes tipos de propuestas editoriales: pymes editoriales, artesanales, cooperativas, unipersonales, "hogareñas". La diversidad de proyectos editoriales puede estar marcada por las escalas económicas, los modelos de negocio, las temáticas que componen el catálogo y la dimensión política de la propuesta editorial.

\footnotetext{
2 De acuerdo al relevamiento llevado a cabo por la Universidad Nacional de Quilmes, actualmente se registran 426 proyectos editoriales independientes activos (Badenes, 2019).

3 Cabe mencionar que el campo es más amplio que la polarización entre conglomerados editoriales y editoriales independientes. En el espacio editorial nacional también cuentan otros actores como, por ejemplo, las editoriales de vanidad (Gazzera, 2016) o las editoriales universitarias, que junto a las independientes, realizan una valiosa contribución a la bibliodiversidad (Badenes, 2014).
} 
Incluso, muchas de las editoriales que nacieron luego del 2000 fueron profesionalizándose (Winik y Reck, 2012) y distintos proyectos que, de alguna manera, nacieron del amateurismo, con los años se convirtieron en empresas de cultura.

Asimismo, al interior del sector editorial independiente pueden encontrarse a las editoriales artesanales. Estos proyectos que conforman un subzona de la edición independiente, con una historia propia y relativa autonomía (Schierloh, 2019), se corren de la lógica de producción industrial. Por tanto, se caracterizan, entre otras cosas, por el trabajo intensivo en la materialidad del objeto libro, la realización de tiradas acotadas y la circulación en espacios no convencionales (Conde y Hafter, 2019). Eric Schierloh (2019) distingue entre las editoriales grandes, medianas o pequeñas que tercerizan la producción; las editoriales híbridas medianas o pequeñas que tercerizan algún aspecto de la producción (como la impresión y la encuadernación) y las editoriales artesanales que poseen sus propios talleres en donde se imprime y se encuaderna. De acuerdo a esta idea, el autor considera que las editoriales artesanales, en su mayoría dueñas de los medios de producción, poseen un mayor grado de independencia que otro tipo de proyectos de producción serializada.

La categoría de editoriales independientes, por tanto, es problemática, puesto que suscita una serie de debates en torno a qué tipos de editoriales se encuentran alcanzadas por este mote o no. Así también, ciertas editoriales eligen identificarse como independientes, mientras que otras no se sienten representados por esta denominación. Al respecto, los autores y editores Hernán López Winne y Víctor Malumián (2016) proponen pensar a la "independencia" como una zona: en diferentes momentos de sus trayectorias, las editoriales pueden estar más cerca o más lejos de esa zona.

Ahora bien, las propiedades del campo generan condiciones desiguales de desarrollo para las pequeñas y medianas editoriales, pues, la posición dominante de los conglomerados complejiza el desarrollo de estos emprendimientos. Especialmente, en lo que respecta a la distribución y comercialización.

Sobre este tema, la Cámara Argentina del Libro (2018) plantea que mientras que en 2016 las primeras tiradas provenientes de pymes editoriales distribuidas a las librerías representaban el $61 \%$ del total del SEC (Sector Editorial Comercial ${ }^{4}$ ), en 2018 el índice bajó a $48 \%$. Esto supone la disminución de la presencia de las pymes editoriales en el canal librero que van optando por otros canales de venta para los primeros ejemplares que lanzan. En esta línea, las primeras ediciones de los grupos editoriales pasaron de representar el $39 \%$ en 2016, al 52\% en 2018 (Cámara Argentina del Libro, 2018). Debido a la reducción de novedades de las pymes en el canal librero y el crecimiento de la presencia de las grandes casas editoriales en este sector, cabe preguntarse "si se está acentuando una concentración

\footnotetext{
${ }^{4}$ La Cámara Argentina del Libro utiliza la clasificación Sector Editorial Comercial (SEC) para referirse a las publicaciones pertenecientes a empresas editoriales dirigidas a canales de venta exclusivos del producto libro (librerías, distribuidoras de libros físicos o digitales, venta directa al público, etc.).
} 
(y por ende una pérdida de bibliodiversidad) en la oferta de novedades que reciben las librerías" (Cámara Argentina del Libro, 2018, p. 27).

Las acciones de las grandes empresas que pueden llegar a acaparar la distribución mayorista y gran parte del espacio en librerías, desafían el funcionamiento de las empresas de pequeña y mediana escala. En estos procesos intermedios orientados a la circulación de libros, entonces, se evidencian las relaciones de poder dentro del campo editorial.

Las editoriales independientes, en consecuencia, se ven obligadas a emplear estrategias de gestión y formas de circulación comercial variadas para sustentarse y subsistir en el mercado.

\section{Distribución tercerizada}

La distribución es un proceso fundamental en el conjunto de actividades que hacen a la circulación y al acceso al libro. Esta actividad combina rasgos técnicos y logísticos que influyen decisivamente en el nivel de ventas, fuente principal de financiamiento de las editoriales. Por tanto, no es menor la incidencia que tiene en la sostenibilidad de las empresas de edición.

Las formas principales en que se lleva adelante la distribución mayorista son: a través de la distribución externa (es decir, contratando a empresas que brindan un servicio de distribución de libros) o apelando a la distribución propia (autodistribución). Cada sistema posee su grado de dificultad, y generan una serie de ventajas y desventajas para los editores independientes.

Por un lado, muchas editoriales independientes apelan a los servicios de una empresa distribuidora para "mover" sus libros. Según el Informe de producción del libro argentino (2019) elaborado por la Cámara Argentina del Libro, en los últimos cuatro años los distribuidores han adquirido importancia entre las pequeñas y medianas editoriales.

Este es el método más tradicional para dar circulación a un catálogo y consiste en la contratación de una empresa que brinda el servicio de distribución. Esto contempla las tareas de recepción de los ejemplares, almacenamiento, preparación de pedidos, armado de cajas, gestión del transporte, verificación de las cuentas de los libreros y facturación y administración de las devoluciones (Colleu, 2008).

Tales acciones hacen que el distribuidor se constituya como un agente intermediario de importancia tanto para la editorial como para las librerías. Por un lado, este agente trabaja con el catálogo de la editorial que lo contrató y se encarga de "posicionar" los libros en las librerías y, por tanto, se encuentra en contacto permanente con el librero, al cual provee de los materiales de trabajo.

Para las editoriales independientes, la distribución tercerizada presenta determinadas ventajas. Principalmente, trabajar con una distribuidora externa a la empresa, libera a la 
editorial de la necesidad de desarrollar una estructura de logística que resulta costosa y requiere de la dedicación de personal abocado específicamente a dicha tarea.

Juan Carlos Manoukian, editor del sello Ediciones CICCUS, plantea que:

La ventaja de contratar la distribución es que me exime como editor de armar una estructura de comercialización propia que es muy engorrosa, muy cara. Si yo no distribuyera de la mano de mis amigos distribuidores tendría que tener por lo menos 5 empleados más que se dediquen a recibir el material, armar los paquetes, llegar a todas las librerías del país. Y generar una estructura administrativa que haga que todos los libros que salen al mercado yo los pueda controlar en el sentido de cuántos salieron, cuántos pagó, cuántos no pagó, cuántos deben... Es muy engorroso. Y eso lo hace el distribuidor que es su especialidad, su laburo (Juan Carlos Manoukian, editor de Ediciones CICCUS).

Asimismo, las empresas de distribución desligan a los editores de las acciones de gestión y administración vinculadas a esta actividad, tales como las cobranzas y los documentos correspondientes (facturas, remitos, etcétera). Esto permite a los editores dedicarse exclusivamente a la producción de los libros y delegar la tarea administrativa correspondiente a la parte comercial. Razón por la cual muchos optan por pagar un servicio de distribución.

La distribución por terceros, entonces, ofrece condiciones favorables para la construcción de mercados. Sin embargo, aparecen determinadas dificultades cuando se trata de pequeños sellos. Muchas veces los resultados de este servicio no son beneficiosos para este tipo de editoriales cuyos catálogos son de rotación lenta, orientados a nichos del mercado y requieren de tiempos largos de posicionamiento. Es decir, los productos de los sellos independientes no funcionan de la misma manera que los libros de los grandes sellos que son más "fáciles" de colocar en librerías -las políticas editoriales de las empresas multinacionales se basan en la búsqueda de éxito inmediato (Danieli, 2006), cuyo paradigma son los bestsellers inspirados en "las modas" del mercado (Badenes, 2014).

Dado que las editoriales independientes se manejan en base a tiradas chicas, destinar la mayor parte a un distribuidor representa una gran apuesta -siendo que, además, cuando las tiradas son reducidas es más difícil acceder a un distribuidor.

A su vez, los tiempos propios de la distribución se tornan largos, repercutiendo en las liquidaciones provenientes de las ventas que llegan a la editorial varios meses después de la declaración del librero. En este punto influye el hecho de que la mayoría de las editoriales independientes envían sus ejemplares en consignación a las librerías. Este sistema consiste en "la entrega por parte de las editoriales de una cantidad de libros a las librerías para que los vendan, con el compromiso de declarar (en forma mensual) las ventas efectivamente realizadas" (Centro de Estudios para la Producción, 2014, p. 58). La consignación, por tanto, prolonga la cadena de pagos, afectando la gestión financiera de las editoriales. 
En otro orden, las distribuidoras mayoristas suelen acaparar gran cantidad de sellos, de modo que trabajan con varias firmas a la vez. En esta estrategia de financiamiento resulta común que los grandes grupos editoriales tengan prioridad por parte de los distribuidores.

El distribuidor nunca se ocupa con ahínco a promover nuestro material. Porque cuando mandan un servicio de novedades el distribuidor incluye uno o dos libro de CICCUS en una caja donde hay libros de 40 editoriales. El problema es que la direccionalidad de ese material no es muy precisa, se manda al voleo. Algunos a Córdoba, a Misiones, a Neuquén y nunca queda claro por qué no le mandó a Rosario, o por qué no atendió esa librería que está al lado de la Universidad de Neuquén o de la Universidad de La Rioja (Juan Carlos Manoukian, editor de Ediciones CICCUS).

Este método de distribución, en consecuencia, no siempre resulta el más adecuado para los pequeños sellos que difícilmente generan bestsellers con registros de ventas por encima de los 30000 ejemplares en un periodo relativamente corto de tiempo (lógicas con las cuales sí se manejan habitualmente los grandes grupos). En este modelo de negocio por el cual las distribuidoras acaparan varios clientes a la vez, tienen privilegio los productos de las grandes casas editoriales. La razón es obvia: los libros de rápida circulación implican más ingresos para el distribuidor y el librero. En consecuencia, hay una menor atención a las pequeñas editoriales.

Como marca Juan Carlos Manoukian, existen imprecisiones en los envíos que hacen los distribuidores. Esto conduce a que muchas veces los editores no conozcan en qué librerías están los libros y, en consecuencia, aparecen las dificultades para cobrarlos, además de la pérdida de ejemplares.

Asimismo, las grandes corporaciones editoriales, valiéndose de su posición dominante en el mercado, poseen mayor capacidad de negociación con los intermediarios comerciales. El respaldo económico con el que cuentan estas empresas les asegura privilegios en las librerías, como mejores exhibiciones, afectando negativamente a los catálogos del resto de los actores editoriales.

Estas condiciones de concentración del mercado, por tanto, ponen en tensión la circulación comercial de los catálogos de las pequeñas y medianas editoriales. Cabe mencionar, además, a las maniobras de concentración vertical por el cual los conglomerados se hacen de imprentas, distribuidoras y librerías. Tales factores desafían la operatividad de las editoriales independientes.

La concentración también sucede en el canal librero. Al respecto, es común que las grandes cadenas de librerías -principalmente Yenny-El Ateneo y Cúspide- exijan mayores descuentos a las editoriales para recibir sus catálogos.

En este punto es necesario marcar la importancia de la Ley 25.452 de Defensa de la Actividad Librera como marco legislativo destinado a ajustar los desequilibrios del mercado. Esta norma dispone al editor como el responsable de establecer un precio uniforme de venta al público (PVP) de los libros que publique, el cual debe ser respetado por los canales 
comerciales en todo el país (Getino, 2008, p.100). La conocida "ley de precio fijo" protegió a las pequeñas y medianas librerías de las maniobras depredatorias de las cadenas de librerías y supermercados que vendían a muy bajo precio, persiguiendo generar condiciones justas de competencia. Además, como plantea el investigador Alejandro Dujovne (2019), esta norma benefició a las editoriales independientes ya que, de manera indirecta, aportó al desarrollo de un "universo editorial independiente".

No obstante, fuera de la experiencia de esta norma, escasean las políticas públicas o medidas gubernamentales que se aboquen a resolver estos desajustes en lo que respecta a distribución. Si bien se aleja del recorte temporal establecido en este artículo, cabe mencionar que el proyecto de ley de creación del Instituto Nacional del Libro Argentino (INLA), presentado en 2019, tiene entre sus objetivos promover la circulación y el acceso federal y democrático al libro. Al momento de la realización del presente escrito, el proyecto se encuentra pausado hasta que se retome su debate legislativo ${ }^{5}$.

En resumen, las condiciones de concentración del campo generan dificultades para las pequeñas editoriales en cuanto a dar circulación a sus producciones y adquirir visibilidad. Esto se ve reflejado muchas veces en el desempeño y los resultados que obtienen de la distribución tercerizada.

\section{Autodistribución: ventajas y dificultades}

Como respuesta a los problemas que genera la distribución tercerizada, algunos editores deciden encarar la tarea por cuenta propia. La autodistribución genera ventajas respecto a la dependencia de un agente distribuidor, a partir de una mayor autonomía en la organización de la circulación. En base a esto se despliegan ciertas condiciones que ponen en valor la decisión y acción directa en la parte comercial.

En principio, el beneficio más reconocible de la autodistribución consiste en la retención del porcentaje que habitualmente se destina a un distribuidor externo, el cual en promedio constituye alrededor del $50 \%$ del precio de venta al público de un libro (Esteves, 2014). Este porcentaje lo comparte el agente distribuidor con el librero. Este descuento, por tanto, es un ingreso relevante para un sello de estructura económica limitada.

Por otra parte, este sistema conduce a un seguimiento detallado del traslado, colocación y comercio de los libros. En otras palabras, este método permite tener el control del stock y de la cadena de pagos.

La distribución propia permite una acción directa en el circuito comercial. A partir de esto es posible un mejor posicionamiento de los libros en los puntos de venta, lo que

\footnotetext{
${ }^{5}$ Para más información sobre este tema revisar: Velázquez, G. (2020). El debate de las políticas públicas. Revista de Editoriales. Disponible en: http://lease.web.unq.edu.ar/wpcontent/uploads/sites/143/2020/09/RdE-2020-web.pdf
} 
significa, en el mejor de los casos, optimizar el rendimiento comercial del proyecto editorial. Así lo plantea Pablo Martillana, editor de Ediciones del Signo:

Producimos 300 de un título, no podemos darle los 300 a una distribuidora y que tal vez queden en un depósito. O que vayan a Yenny, que queden clavados 20 libros en una librería. Para nosotros 20 de 300 libros es muchísimo. Entonces, no tenés control de lo que pasa con la distribuidora. Haciéndolo nosotros, más a mano, es más controlado. Por ejemplo, pusimos 5 en una librería y vemos cómo funcionó. Tal vez tenemos trato directo con el librero y si vemos que no lo vendió, y que en otras se acabaron, podemos pedir "devolvemelos, se los llevamos a otra" (Pablo Martillana, editor de Ediciones del Signo).

La autodistribución parece ser la forma más adecuada para los sellos con fondos editoriales pequeños, en términos de mejores resultados comerciales. Permite tener un seguimiento fino de las ventas de cada libro y, a la vez, un retorno económico más rápido dado que no hay mediadores entre la editorial y el librero.

Además, abre la oportunidad de un contacto directo con los libreros. Esto no resulta menor ya que muchos editores generan redes con los libreros, a quienes consideran "socios comerciales" (González, 2019).

Adoptar la distribución por cuenta propia trae diversos resultados positivos para los editores independientes, pero la contracara de este sistema es la alta carga financiera y laboral que implica para los gestores del sello. La autodistribución requiere de una gran inversión y, sobre todo, una dedicación intensiva de los miembros de la editorial (Velázquez, 2018). En este punto, cuentan las tareas de administración del almacenamiento que implican actividades como contar el stock, organizar cajas, armar pedidos.

Los costos de inversión en este aspecto corresponden al montaje de toda una estructura logística. Se puede mencionar, entre otras cosas, empleo de fletes, el armado y acondicionamiento de los depósitos, materiales para la preparación de pedidos como cajas o cinta de embalar, contratación de personal. Hacerse cargo de la distribución, además, supone desarrollar una estructura administrativa dedicada a llevar las cuentas, armar remitos, visitar las librerías, gestionar las reposiciones y las devoluciones. Para resolver todo ello se destinan altos niveles de capital que sólo se justifica cuando la editorial ha alcanzado una determinada escala financiera.

Por otra parte, también deben considerarse los altos costos de envío de paquetes. Los editores muchas veces envían libros a librerías de distintos puntos del país a precios que, algunas veces, hasta pueden superan a los costos de la realización del ejemplar. Dicho problema afecta a la distribución al, y desde, el interior del país.

La Cámara Argentina del Libro sostiene un acuerdo con las firmas Correo Argentino y DHL que otorga descuentos en los envíos de paquetes para sus socios. No obstante, según relata Pablo Martillana, este descuento no abarata demasiado los altos costos de envío.

Cada forma, distribución tercerizada o autodistribución, tiene sus aspectos positivos y negativos. Los sellos editoriales deben escoger entre las opciones más apropiadas para sus 
productos. Sin embargo, los niveles de concentración de la industria, introducen más complejidad a la distribución. Las pymes editoriales resultan las más afectadas, dado que tienen menor capacidad de incidencia en el canal comercial.

\section{Asociación entre editoriales independientes}

Como reacción a las distintas problemáticas que se le presentan a las editoriales independientes, en los últimos tiempos se han ampliado diferentes iniciativas asociativas. Estas prácticas suponen la alianza de dos o más editores en pos de superar en conjunto dificultades que por sí solos no podrían, particularmente en lo que respecta a distribución (Velázquez, 2019).

En este aspecto, pueden mencionarse las distribuidoras que han nacido de este tipo de experiencia como, por ejemplo, La Coop, Malisia y Carbono, entre otras. Dichas propuestas surgen de la unión de editores para resolver en conjunto un problema sensible como lo es la circulación mayorista. Estas distribuidoras de editoriales independientes funcionan en base a una distribución selectiva en determinados puntos de venta, en busca de una circulación comercial medida y eficiente.

Resulta relevante mencionar que este tipo de alianzas también se llevan adelante en las ferias. Las ferias representan una vía significativa de venta minorista a la cual apelan muchas las editoriales independientes. Estos eventos permiten realizar ventas directas, lo que significa retener el porcentaje que habitualmente se destina al canal comercial.

Ahora bien, la participación en algunas ferias implica mucha inversión. La Feria Internacional del Libro de Buenos Aires (FIL), como otras instancias similares, supone un determinado costo por metro cuadrado de stand que, muchas veces, un sello de manera particular no puede costear. En consecuencia, muchos editores apelan a compartir los gastos alquilando colectivamente stands. De esta manera amortizan los costos y se aseguran la presencia en la feria. Existen stands compartidos con amplia trayectoria en este sentido como Sólidos Platónicos -Aquilina, Criatura, Ediciones Godot, Gourmet Musical, Letranómada, Libraria, Paprika, Fiordo y Wolkowicz Editores-, Los Siete Logos -Adriana Hidalgo, Beatriz Viterbo, Caja Negra, Criatura, Eterna Cadencia, Katz y Mardulce- y Asunto Impreso -Marea Editorial, Asunto Impreso, Ediciones Factotum, La marca editorial e Interzona. También se destaca la reciente asociación Cardumen creada para participar de la Feria Internacional del Libro de Buenos Aires en 2019, la cual integra Ediciones del Signo junto a Madreselva, Cúlmine, Herramienta, El colectivo, Carretilla Roja, Letra Sudaca, Rara Avis, Inerme Libros, El Ágora, Alter ediciones, Editorial Biblioteca Vigil, Cantamañanas, Saraza, Valija de Fuego y Pol-len.

En su gran mayoría, las editoriales independientes participan de la FIL, con stand individual o colectivo. De las 18 editoriales relevadas para la tesis antes mencionada, la 
mayoría participa de este evento. Esto adquiere relevancia ya que una porción importante del conjunto de actores de este sector participan de las tres ferias principales, la FIL, la Feria del Libro Independiente y Autogestivo (FLIA) y la Feria de Editores (FED); que como demuestra en su tesis Federico Eduardo Urtubey (2018), poseen tres modelos diferentes. En principio, la FIL posee un modelo asociado a la lógica empresarial, relacionado a las corporaciones editoriales. La FLIA, nacida como contraferia a la FIL, se asentó en los principios de gratuidad en el ingreso y la libertad de puestos (Winik, 2010). Asimismo, la FLIA "se extiende hacia una territorialidad incluso callejera (ya que en ocasiones ha tenido lugar en espacios abiertos como parques) y que involucra diversas manifestaciones de lo artesanal y la cultura colaborativa" (Urtubey, 2018, p.99). Por último, la FED se caracteriza por ejercer una selección de las editoriales participantes. A diferencia de la FLIA, que propone la libre participación, la FED apunta a "promover proyectos editoriales 'más consolidados', y por qué no, más especializados" (Urtubey, 2018, p.77).

Por tanto, acceder a un tipo de feria como la Feria Internacional del Libro de Buenos Aires, o incluso encontrar espacios en las grandes cadenas libreras como Yenny, no es condición de "pérdida de independencia". Sino, más bien, son movimientos al interior del segmento independiente, que reflejan la trayectoria profesional de los editores. En este sentido, Daniela Szpilbarg (2015) demuestra que gran parte de las posiciones y separaciones de estos agentes tiene mucho que ver con los ámbitos de circulación que propician, asociadas a un determinado modelo de distribución y comercialización. Dichos espacios pueden ser el circuito under-autogestivo ligado principalmente a la FLIA, el circuito tradicional del mercado asociado a la presencia en librerías de cadena, el espacio de librerías independientes o, incluso, la venta a través de Internet. La intervención de los editores en alguno de estos circuitos o, lo que es más común, en varios a la vez, escapa a la dicotomización del espacio editorial en dos polos y permite pensar, por un lado, en una complejización del campo y, por otro, en la profesionalización de estas editoriales (Szpilbarg, 2015, p.19).

Por último, cabe mencionar a las ferias organizadas por editoriales independientes, las cuales han adquirido relevancia en los últimos años, a la par del crecimiento de este tipo de sellos. Se destacan, además de la FLIA y la FED, la feria EDITA y la Fiesta del Libro y la Revista. Estos espacios se han posicionado como eventos de relevancia para los pequeños sellos y para los lectores. La proliferación de este tipo de ferias organizadas por editoriales independientes constituye tanto una vía de intervención de los editores, como un punto de encuentro directo entre estos actores y los lectores.

La formación de alianzas editoriales, por tanto, se torna una metodología significativa para hacer frente a las dificultades del mercado. En las experiencias de alianzas editoriales se ponen en juego estrategias equitativas donde los editores se ayudan entre sí, comparten conocimientos, generan eventos y actividades culturales. Volviendo al esquema de Darnton, 
es posible plantear que la asociación entre agentes que comparten igual posición en el campo y, por ende, afrontan las mismas dificultades, construye una trama de relaciones en red. Estas prácticas que no sólo alcanzan a editores, sino también a libreros, imprenteros y distribuidores, aportan dinamismo al campo.

\section{Reflexiones finales}

La distribución se presenta como una etapa fundamental del proceso editorial, puesto que encierra un conjunto de acciones que hacen a la circulación de los libros. Esta actividad influye decisivamente en el nivel de ventas, por tanto, no es menor la incidencia que tiene la distribución comercial en la sostenibilidad de las empresas de edición.

Los sistemas vinculados a la circulación representan una complejidad para el campo editorial. En este problema entra en juego la concentración del mercado a partir de la cual las empresas editoriales de enorme peso económico y simbólico poseen una posición dominante dentro del campo. Esto hace que los grupos concentrados adquieran una mayor atención de los distribuidores y libreros, lo que se traduce en una mayor dedicación en la colocación y seguimiento de los libros en los puntos de venta.

Aquí se pone en evidencia la distribución desigual de capitales simbólicos y económicos, puesto que los actores de menor tamaño se encuentran en situación de desventaja.

A raíz de estas condiciones del campo, las editoriales del sector independiente se caracterizan por apelar a distintas estrategias para brindar circulación a sus materiales. Acciones cercanas a la autogestión, entre las cuales se destacan las estrategias asociativas para dar solución a determinados problemas comunes. Estas alianzas pueden adquirir cuerpo a partir de la formación de distribuidoras colectivas o la participación en ferias a través de stands colectivos. Este tipo de prácticas habilitan el encuentro entre editores y, por tanto, enriquecen el ecosistema editorial.

A partir de las acciones de las editoriales independientes, actores relevantes de la industria editorial nacional, se procesa una trama de relaciones en red, un conjunto de prácticas que dinamizan al campo.

\section{Referencias bibliográficas}

Badenes, D. (17 de septiembre, 2014). La resistencia de los editores. Página/12. Recuperado de: http://www.pagina12.com.ar/diario/laventana/26-255501-2014-09-17.html Badenes, D. (2019). La edición imperfecta. En Badenes, D. y Stedile Luna, V. (comps.). Estado de Feria Permanente. La experiencia de las editoriales independientes argentinas 2001-2020 (pp. 21-44). La Plata: Club Hem Editores. 
Botto, M. (2006). La concentración y la polarización de la industria editorial. En José Luis de Diego (dir.). Editores y políticas editoriales en Argentina 1880-2000. Buenos Aires: FCE. Bourdieu, P. (2000). Una revolución conservadora en la edición. En Intelectuales, política y poder. Buenos Aires: Eudeba.

Bourdieu, P. (2002). Campo Intelectual y Proyecto Creador. En Campo de Poder, Campo Intelectual. Itinerario de un concepto. Buenos Aires: Montressor.

Cámara Argentina del Libro (2018). Informe de producción del libro argentino. Recuperado (11 de agosto de 2020), https://www.camaradellibro.com.ar/index.php/panoramaeditorial/estadisticas

Cámara Argentina del Libro (2019). Informe de producción del libro argentino. Recuperado (11 de agosto de 2020), https://www.camaradellibro.com.ar/index.php/panoramaeditorial/estadisticas

Centro de Estudios para la Producción. (2014). La industria del libro en Argentina.

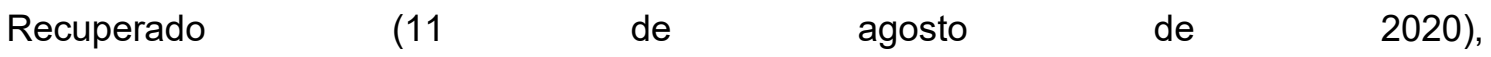
http://www.funcex.org.br/material/REDEMERCOSUL_BIBLIOGRAFIA/biblio teca/ESTUDOS_ARGENTINA/ARG_51.pdf Colleu, G. (2008). La edición independiente como herramienta protagónica de la bibliodiversidad. Buenos aires: La marca Editora.

Conde, J. y Hafter, L. (2019). Hacia una categoría de edición-arte. En Badenes, D. y Stedile Luna, V. (comps.). Estado de Feria Permanente. La experiencia de las editoriales independientes argentinas 2001-2020 (pp. 21-44). La Plata: Club Hem Editores.

Danieli, A. (2006). Edición independiente: Estrategias para la diversidad. En Moneta, C. (comp.). El jardín de los senderos que se encuentran: Políticas públicas y diversidad cultural en el MERCOSUR. Montevideo: Unesco.

Darnton, R. (2010). ¿Qué es la historia del libro? En: El beso de Lamourette. Reflexiones sobre historia cultural. Buenos Aires: Fondo de Cultura Económica.

De Souza Muniz Júnior, J. D. (2015). Itinerarios de una identidad voluble: el debate sobre la edición. Orbis Tertius; 20 (21), 145-158.

Dujovne, A. (2017). La aventura intelectual de publicar un libro. Anfibia. Recuperado de: http://www.revistaanfibia.com/ensayo/la-aventura-intelectual-de-publicar-unlibro/

Dujovne, A. (2019). Epílogo. En Badenes D. y Stedile Luna, V. (comps.). Estado de feria permanente. La experiencia de las editoriales independientes argentinas 2001-2020 (pp. 293-298). La Plata: Club Hem Editores.

Esteves, F. (2014). Manual de supervivencia para editores del siglo XXI. Buenos Aires: Eudeba.

Gazzera, C. (2016). Editar: un oficio: Atajos/Rodeos/Modelos. Córdoba: Eduvim.

Getino, O. (2008). El capital de la cultura. Las industrias culturales en la Argentina. Buenos Aires: CICCUS. 
González, N. (2019). Nuestros socios, los libreros. La importancia de la ocupación territorial. En Badenes D. y Stedile Luna, V. (comps.). Estado de feria permanente. La experiencia de las editoriales independientes argentinas 2001-2020 (pp. 283-292). La Plata: Club Hem Editores.

López Winne, H. y Malumián, V. (2016). Independientes, ¿de qué? Hablan los editores de América Latina. México: Fondo de Cultura Económica.

Saferstein, E. (2014). El "sentido práctico del editor": Transformaciones y tensiones en el rol del Director Editorial de las grandes empresas en Argentina. Prácticas de oficio. Investigación y reflexión en Ciencias Sociales (14).

Saferstein, E. y Szpilbarg, D. (2014). La industria editorial Argentina 1990-2010: entre la concentración económica y la bibliodiversidad. Alternativa (3).

Schierloh, E. (junio de 2019). Sobre la independencia editorial (con coordenadas para evaluarla)

Mímesis.

Recuperado

de:

https://edicionesmimesis.cl/index.php/2019/06/19/sobre-la-independenciaeditorial-con-

coordenadas-para-evaluarla-por-

ericschierloh/?fbclid=IwAR1_xKPeGFPSQbgyahgYQ4O9bkpdwJfHTQCH22L0JbbVSU7SG eimgMc78WU

Szpilbarg, D. (2015). Independencias en el espacio editorial argentino de los 2000: genealogía de un espejismo conceptual. Estudios de Teoría Literaria, 4 (7), 7-21.

Szpilbarg, D. (2019). Cartografía Argentina de la edición Mundializada. Modos de hacer y pensar el libro en el siglo XXI. Buenos Aires: Tren en Movimiento.

Urtubey, F. E. (2018). La trama de la edición. Estética y política en tres editoriales artesanales pos 2001. (Tesis de posgrado). La Plata: Universidad Nacional de La Plata.

Vanoli, H. y Saferstein, E. (2011). Cultura literaria e industria editorial. Desencuentros, convergencias y preguntas alrededor de la escena de las pequeñas editoriales. En Rubinich, L. y Miguel, P. (eds.). Creatividad, economía y cultura en la ciudad de Buenos Aires 20012010 (pp. 1-10). Buenos Aires: Aurelia Rivera.

Velázquez, G. (2019). La distribución asociada: alianzas contingentes y proyectos consolidados. En Badenes D. y Stedile Luna, V. (comps.). Estado de feria permanente. La experiencia de las editoriales independientes argentinas 2001-2020 (pp. 265-282). La Plata: Club Hem Editores.

Velázquez. G. (2018). La distribución en la industria del libro. Hacia una caracterización. Memorias de las Jornadas Nacionales de Investigadores en Comunicación, Red Nacional de Investigadores en Comunicación.

Winik, M. (2010). Experimento FLIA. Jornadas Producción cultural, nuevos saberes e imaginarios en la sociedad argentina contemporánea, a la luz de la Globalización. Instituto de Investigaciones Gino Germani, Universidad Nacional de Buenos Aires. 
Winik, M. y Reck, M. (2012). Un posible final para un certero inicio: acerca de los nuevos desafíos de las editoriales independientes. Primer Coloquio Argentino de Estudios sobre el Libro y la Edición, La Plata. Recuperado de: http://www.memoria.fahce.unlp.edu.ar/library?a=q \&r=1\&hs=1\&css=1\&c=all\&t=0\&q=Coloqui $o+$ Argentino + de + Estudios + sobre + el + Libro $+y+l a+E d i c i \% C 3 \% B 3 n \& f q f=D T \& j=m e \& c c=e v e n t$ os\&sf= 